\title{
A New Minimal-Stress Freely-Moving Rat Model for Preclinical Studies on Intranasal Administration of CNS Drugs
}

\author{
Jasper Stevens, ${ }^{1}$ Ernst Suidgeest, ${ }^{1}$ Piet Hein van der Graaf, ${ }^{2}$ Meindert Danhof, ${ }^{1}$ and Elizabeth C. M. de Lange ${ }^{1,3,4}$
}

Received March 4, 2009; accepted May 7, 2009; published online May 19, 2009

\begin{abstract}
Purpose. To develop a new minimal-stress model for intranasal administration in freely moving rats and to evaluate in this model the brain distribution of acetaminophen following intranasal versus intravenous administration.

Methods. Male Wistar rats received one intranasal cannula, an intra-cerebral microdialysis probe, and two blood cannulas for drug administration and serial blood sampling respectively. To evaluate this novel model, the following experiments were conducted. 1) Evans Blue was administered to verify the selectivity of intranasal exposure. 2) During a 1 min infusion 10, 20, or $40 \mu \mathrm{l}$ saline was administered intranasally or $250 \mu \mathrm{l}$ intravenously. Corticosterone plasma concentrations over time were compared as biomarkers for stress. 3) $200 \mu \mathrm{g}$ of the model drug acetaminophen was given in identical setup and plasma, and brain pharmacokinetics were determined.

Results. In $96 \%$ of the rats, only the targeted nasal cavity was deeply colored. Corticosterone plasma concentrations were not influenced, neither by route nor volume of administration. Pharmacokinetics of acetaminophen were identical after intravenous and intranasal administration, although the Cmax in microdialysates was reached a little earlier following intravenous administration.

Conclusion. A new minimal-stress model for intranasal administration in freely moving rats has been successfully developed and allows direct comparison with intravenous administration.
\end{abstract}

KEY WORDS: acetaminophen; brain; intranasal infusion; microdialysis; pharmacokinetics.

\section{INTRODUCTION}

Targeting the central nervous system (CNS) by intranasal delivery is a promising alternative for oral or parenteral administration, and is investigated to directly target the brain, thereby increasing CNS target site bioavailability and the efficacy of CNS drugs (1-3). Little is known however on the distribution of CNS drugs into the target site, i.e. the extracellular fluid (ECF) surrounding the pharmacologic receptors in brain tissue, following intranasal administration.

Current pharmacokinetic-pharmacodynamic (PK-PD) studies after intranasal administration in small laboratory animals are performed with anaesthetized animals, whether or not in combination with complete isolation of the nasal cavity and a cannulated trachea to aid breathing (4-7). Other research is based upon restrained animals(8). All methods currently used have major influence on physiology (i.e. blood flow, nasal immunology, mucociliary clearance, nasal cycle,

\footnotetext{
${ }^{1}$ Division of Pharmacology, LACDR Leiden University, Leiden, The Netherlands.

${ }^{2}$ Pfizer Global Research and Development, Sandwich, Kent, England.

${ }^{3}$ LACDR/Pharmacology, Gorlaeus Laboratories, Leiden University, Einsteinweg 55, 2333 CC, Leiden, The Netherlands.

${ }^{4}$ To whom correspondence should be addressed. (e-mail: 1.lange@ lacdr.leidenuniv.nl)
}

airflow dynamics, and stress), which all play important roles in the PK and/or PD of compounds (9-17). Therefore, this methodology complicates quantification of PK-PD endpoints and consequently the extrapolation to the in-vivo human situation.

To meet the demands for animal PK/biomarker models and nasal administration techniques, which allow better interpretation and translation of PK-PD parameters from animal to man, a new animal model is needed that allows drug administration under minimal stress conditions in freely moving animals.

The objective of this study was to develop and validate a new preclinical, refined minimal stress animal model, in which we can administer compounds intranasally and intravenously, while blood- and brain ECF samples can be taken over time, to obtain PK-PD parameters in plasma and brain of freely moving animals. After comparing the size of nasal cavities, the highly vascular olfactory epithelium ratios, and costconsiderations of eight different species, as described by Ugwoke et al. (17), we focused on the rat as animal of choice. An intranasal cannula was manufactured and implanted together with an intracerebral microdialysis probe. Also the animals received two blood cannulas for drug administration and serial blood sampling respectively. The intranasal site of administration needed to be substantiated by a staining study. Through corticosterone measurements and comparison with literature, any stress effects during our experimental- and administration techniques had to be excluded (18). Then, our 
model had to be validated, which was done by the administration of a model compound and comparing the pharmacokinetics between the groups. Acetaminophen was used for its linear plasma and BBB transport kinetics (19-23). Pglycoprotein (P-gp) efflux did not have to be considered since acetaminophen is no $\mathrm{P}$-gp substrate (20-22). To explain concentration time profiles and include both intraindividual and interindividual variability, pharmacokinetic modelling was used to calculate population parameter estimates of blood- and brain PK.

\section{MATERIALS AND METHODS}

\section{Surgery and Methods}

All animal procedures were performed in accordance with Dutch laws on animal experimentation. The study protocol was approved by the Animal Ethics Committee of Leiden University (UDEC nr. 6023 and 6132). Male Wistar WU rats $(245 \pm 18 \mathrm{~g}$, Charles River, The Netherlands), $n=89$, were housed in groups for 7-13 days (Animal Facilities, Gorlaeus Laboratoria, Leiden, The Netherlands), under standard environmental conditions (Ambient temperature $21^{\circ} \mathrm{C}$; humidity $60 \%$; $12 / 12 \mathrm{~h}$ light, background noise, daily handled), with ad libitum access to food (Laboratory chow, Hope Farms, Woerden, The Netherlands) and acidified water. Between surgery and experiments, the animals were kept individually in Makrolon type three cages for 7 days to recover from the surgical procedures.

All surgical procedures were performed under complete anesthesia with subcutaneous administration of $0.1 \mathrm{ml} / 100 \mathrm{~g}$ Ketanest (ketamine base $25 \mathrm{mg} / \mathrm{ml}$, Pfizer B.V., Capelle a/d Ijssel, the Netherlands), and $0.01-0.017 \mathrm{ml} / 100 \mathrm{~g}$ Domitor (medetomidine hydrochloride $1 \mathrm{mg} / \mathrm{ml}$, Pfizer Animal Health B.V. Capelle a/d Ijssel, The Netherlands). Body temperature was maintained at $37^{\circ} \mathrm{C}$ by an electric heating pad. All cannulas were disinfected with $0.1 \%$ benzalkoniumchloride.

The animals were chronically instrumented with a CMA/ 12 microdialysis guide (Aurora Borealis Control, Schoonebeek, The Netherlands) in the olfactory bulb. The guide was inserted at $53^{\circ}$ from the dorsoventral axis (towards posterior) parallel to the sagittal plane, at the coordinates AP $-2.5 \mathrm{~mm}$, $\mathrm{L}-0.9 \mathrm{~mm}, \mathrm{~V}-6.4 \mathrm{~mm}$ from bregma. The intranasal probe was manufactured (Fig. 1) by bending the sawn off tip of a 27 gauge needle $\left(90^{\circ}\right)$ and glueing the blunt end to $10 \mathrm{~cm}$ tubing (Portex Fine Bore polythene tubing, Smiths Industries, Kent England). With a $1.0 \mathrm{~mm}$ drill, a hole was drilled through the

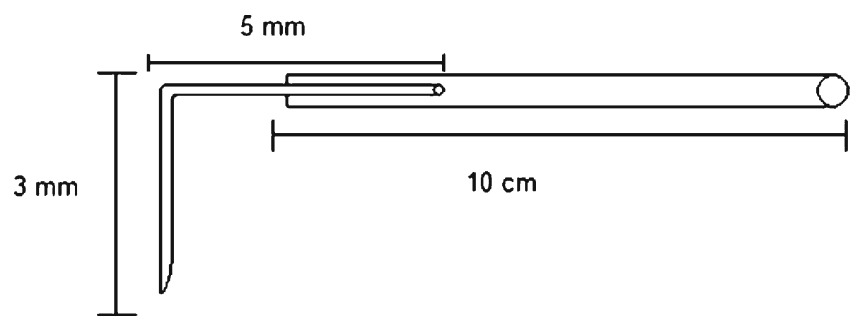

Fig. 1. Schematic representation of the intranasal cannula. The $0.28 \mathrm{~mm}$ internal diameter, and $0.61 \mathrm{~mm}$ outer diameter tubing is glued to the bended $\left(90^{\circ}\right)$, sawn off tip of a 27 gauge needle. nasal bone (AP $12 \mathrm{~mm}$ and $\mathrm{L}-0.5 \mathrm{~mm}$ ), the metal tip was pressed into the hole and attached with histo-acryl (B. Braun Medical B.V., Oss, The Netherlands). The nasal cannula was tunneled subcutaneously to the back of the head. The end was melted shut to prevent infection. Consequently, the animals received two cannulas. To obtain blood samples, $3 \mathrm{~cm}$ of ID $0.28 \mathrm{~mm}$ cannula (SIMS Portex LTD, England) was inserted in the femoral artery, connected to $16 \mathrm{~cm} \mathrm{x}$ $0.58 \mathrm{~mm}$ internal diameter (ID) cannula (Portex Fine Bore polythene tubing Smiths Industries, Kent England,). For drug administration, $4 \mathrm{~cm}$ of ID $0.58 \mathrm{~mm}$ cannula was inserted in the femoral vein, and $16 \mathrm{~cm}$ of ID $0.58 \mathrm{~mm}$ cannula was, similar to the sampling cannula, led subcutaneously to the back of the head where it was fixated with a rubber ring.

After the surgery the animals received $0.03 \mathrm{ml}$ Temgesic $®$ intramuscular (Schering-Plough, The Netherlands) and $0.3 \mathrm{ml}$ Ampicillan ${ }^{\circledR}$ (Alfasan B.V. Woerden) subcutaneously. After 6 days the guide was replaced by the microdialysis probe (CMA/12, $4 \mathrm{~mm}$ Polycarbonate membrane, cut-off $20 \mathrm{kD}$ ) at a pre-experiment interval of $24 \pm 1 \mathrm{~h}$.

In the corticosterone study, a control group of seven rats received $500 \mu \mathrm{l}$ intravenously administered saline (B. Braun Melsungen AG, Melsungen, Germany) during a 1-minute infusion with an automated pump (Harvard apparatus 22, model 55-2222, Holliston, MA, USA). The experimental groups received 10,20 , or $40 \mu \mathrm{l}$ of saline intranasally $(n=8,10$, and 9 respectively). Blood samples of $200 \mu \mathrm{l}$ were taken from the arterial cannula at $t=0$ (blank), 5, 10, 20, 35, 60, 90, 120, 150 , and $180 \mathrm{~min}$, shaken in heparin (10 IE) coated eppendorfcups (Sarstedt, Nümbrecht, Germany), and temporarily stored on ice. After the experiment the samples were centrifuged for $15 \mathrm{~min}$ at $5,000 \mathrm{rpm}$ and stored at $-20^{\circ} \mathrm{C}$.

Using the aforementioned automated pump, in the acetaminophen study the control group received a dose of $200 \mu \mathrm{g}$ acetaminophen (Leiden University Medical Center Pharmacy, Leiden, The Netherlands) in $250 \mu \mathrm{l}$ saline intravenously in $30 \mathrm{~s}$. In the experimental groups, $200 \mu \mathrm{g}$ acetaminophen in 20,30 , or $40 \mu \mathrm{l}$ saline was administered intranasally during a $1 \mathrm{~min}$ infusion. Start and duration of infusion was corrected for internal volume of the tubing so that infusion started at $t=0 \mathrm{~min}$. Blood samples of $200 \mu \mathrm{l}$ were taken from the arterial cannula at $t=0$ (blank), 5, 10, 20, 35, 60, 90, 120, 150 , and $180 \mathrm{~min}$, and temporarily stored in heparin (10 IE) coated eppendorfcups on ice. After the experiment the samples were centrifuged for $15 \mathrm{~min}$ at 5,000 rpm and stored at $-20^{\circ} \mathrm{C}$.

Microdialysis perfusion fluid (PF) was prepared (24), consisting of phosphate buffer ( $2 \mathrm{mM}, \mathrm{pH} 7.4)$, containing $145 \mathrm{mM}$ sodium, $2.7 \mathrm{mM}$ potassium, $1.2 \mathrm{mM}$ calcium, $1.0 \mathrm{mM}$ magnesium, $150 \mathrm{mM}$ chloride, and $0.2 \mathrm{mM}$ ascorbate, which was filtered, stored in glass vials $\left(-20^{\circ} \mathrm{C}\right)$, and sonified before use. Tubing $(1.2 \mu \mathrm{l} / 100 \mathrm{~mm}$ FEP-tubing CMA/Microdialysis AB, Stockholm, Sweden) was connected with tubing adapters (CMA/Microdialysis, Stockholm, Sweden) to the microdialysis probe's inlet and outlet. Microdialysis vials were preweighed and placed in a cooled fraction collector (Univentor 820 Microsampler, Antec, Netherlands) to collect the microdialysate samples. Microdialysis probes were continuously flushed with PF ( $2 \mu \mathrm{l} / \mathrm{min}$, Bee-Hive, Bioanalytical Systems Inc. W-Lafayette, USA), and $10 \mathrm{~min}$ interval samples were collected between $t=-1 \mathrm{~h}$ to $t=1 \mathrm{~h}$, followed by $20 \mathrm{~min}$ 
interval samples until $t=3 \mathrm{~h}$. After sample collection, vials were weighed to determine true probe perfusion rate (a maximal deviation of $5 \%$ was allowed for the sample to be included in the data), and stored at $-80^{\circ} \mathrm{C}$.

In 27 rats of the intranasal groups, $30 \mu \mathrm{l} 0.5 \%$ Evan's blue was administered in $30 \mathrm{~s}$ at the end of the experiments. 10 to $15 \mathrm{~min}$ later, the animals were sacrificed with an overdose of Nembutal (Ceva Sante Animale, Naaldwijk, The Netherlands). The nose tip, nasal cavities, brain, mouth, lungs, and intestines were visually examined for blue coloration and scored on a scale; 3, 2, 1, and 0, representing full, medium, light, and no coloration respectively.

\section{Analysis}

For the plasma corticosterone (CORT) concentrations, a commercially available ${ }^{125} \mathrm{I}$-corticosterone Radio Immunoassay (RIA) was used (ImmunoChem ${ }^{\mathrm{TM}}$ Double Antibody Corticosterone ${ }^{125}$ I RIA kit, MP Biomedicals, Orangeburg, NY, USA), according to the instructions of the manufacturer. Data acquisition was performed on a Gamma Scintillation Counter (Minaxi 5000 series, Packard). Concentrations were calculated using $\mathrm{R}$ 2.5.0 (The R Foundation for Statistical Computing, Vienna, Austria). Data exceeding 1.5 times the interquartile range was excluded from the dataset. Geometric means of the CORT concentrations for the control group and all the animals at $t=0$ was calculated, and compared with literature to determine the amount of stress induced by our operational and handling techniques. Heteroscedasticity was eliminated by calculating logarithmic conversion of the data $(25,26)$, and data were normalized to their own baseline to minimize interindividual variability. Thereafter, the groups were tested at every time point by a single factor ANOVA to determine the amount of stress induced by our experimental techniques.

Acetaminophen concentrations in plasma and microdialysate were determined using High Pressure Liquid Chromotography with Electro-Chemical Detection (HPLC-ECD). For all procedures Purified Millipore water (MQ, resistivity 18.2 $\mathrm{M} \Omega . \mathrm{cm}$ ) from a Milli-Q® PF Plus system was used (Millipore B.V., Amsterdam, The Netherlands). Sigma, Zwijndrecht, The Netherlands delivered 3,4-Dihydroxybenzylamine hydrobromide (DHBA), L-cycteine, and 1-octane-sulfonic acid (OSA). Ethylenediaminetetraacetic acid (EDTA), Perchloric acid, Sodiumacetate, and L-(+)-Ascorbic acid were obtained from Baker, Deventer, The Netherlands. Ortho-Phosphoric acid, diSodium hydrogen phosphate dihydrate, and Sodium dihydrogen phosphate monohydrate were obtained from Merck, Amsterdam, The Netherlands. Methanol and Acetic acid from Biosolve B.V., Valkenswaard, The Netherlands. Calibration solutions were prepared by adding $50 \mu \mathrm{l}$ blank plasma to $50 \mu \mathrm{l}$ calibration standard; 10, 25, 50, 100, 200, 300, 400, 500, and $1,000 \mathrm{ng} / \mathrm{ml}$ acetaminophen in antioxidant (0.1 M Acetic Acid, 3.3 mM L-cysteine, 0.27 M EDTA, 0.0125 mM L-(+)-Ascorbic acid, S. Sarre, personal communications).

To $50 \mu \mathrm{l}$ of the plasma samples $50 \mu \mathrm{l} \mathrm{MQ}$ was added. To these samples $25 \mu \mathrm{l}$ internal standard (IS), containing $150 \mathrm{ng} /$ $\mathrm{ml}$ DHBA, was added and proteins were precipitated by adding $100 \mu \mathrm{l} 6 \%$ Perchloric acid. After vortexing and centrifugation (10 $\mathrm{min}$ at $4000 \mathrm{rpm})$, the supernatant was transferred into a clean glass tube; $150 \mu 11$ M Sodiumacetate was added, and after vortexing, injected into the HPLC-ECD. $20 \mu \mathrm{l}$ of the microdialysate samples was vortexed with $20 \mu \mathrm{l}$ IS and directly injected into the HPLC-ECD system.

The analytical equipment consisted of a LC-10 AD pump (Shimadzu, 's Hertogenbosch, The Netherlands), a Waters 717plus Autosampler (Waters, Etten-Leur, The Netherlands), a pulse damper (Antec Leyden, Zoeterwoude, The Netherlands), a C18 ODS Ultrasphere $5 \mu \mathrm{m}$ column (4.6 mm x $15 \mathrm{~cm}$ ) with $\mathrm{C} 18$ refill guard column (Alltech Netherlands B. V., Ridderkerk, The Netherlands), an electrochemical amperometric detector (DECADE, software version 3.02, Antec Leyden B.V., Zoeterwoude, The Netherlands), a VT-03 electrochemical flow cell, $25 \mu \mathrm{m}$ spacer, and in situ $\mathrm{AG} / \mathrm{AgCl}$ (ISAAC) reference electrode (filled with a saturated potassiumchloride solution) operating in DC mode. The mobile phase (MP) consisted of a $85 \%$ Phosphate buffer $(96,4 \%$ 1.0 M NaH2PO4, 3,6\% $1.0 \mathrm{M} \mathrm{Na} 2 \mathrm{HPO} 4$, diluted with MQ to $50 \mathrm{mM}$ Phosphate buffer, and OSA was added to obtain $2 \mathrm{mM}$ OSA), $15 \% \mathrm{MeOH}$ and $100 \mathrm{mg} / \mathrm{l}$ EDTA. MP was filtered through a $0.2 \mu \mathrm{m}$ nylon filter membrane (Alltech Netherlands B.V., Ridderkerk, The Netherlands).

Data acquisition and processing was performed using Empower® data acquisition software (Waters, Etten-Leur, The Netherlands). For constructing the calibration curve, linear regression analysis was applied using weight factor 1/ $(y)^{2}$. Data exceeding 1.5 times the interquartile range were excluded from the dataset before plotting geometric mean concentrations over time. Data analysis, statistical analysis, and plotting was performed using Microsoft ${ }^{\circledR}$ Office Excel 2003 (Microsoft Corporation, USA) and OriginPro ${ }^{\circledR} 7.5$ (OriginLab Corporation, Northhampton, MA, USA).

Heteroscedasticy was eliminated before executing a single factor ANOVA on every time point $(25,26)$. When $p<0,05$, a Student T-test (one-tailed homoscedastic) was performed between the individual groups per time point. Areas Under the Curve (AUC) were calculated by the trapezoidal rule and microdialysis AUC's were corrected for in vitro recovery. AUC's were plotted, and tested for differences between groups by single factor ANOVA. The absolute recovery was calculated by dividing the plasma AUC after IN administration by the plasma AUC after IV administration.

Nonlinear mixed effect modelling (NONMEM 6.2, run in the PSN module (27) under Windows XP Professional 2002 (service pack3) on an Intel Pentium D CPU3.2 GHz processor) was used to model the pharmacokinetic parameters clearance and volume of distribution. 1-, 2- and 3-compartment models were entered in various subroutines in NONMEM for the experiments with acetaminophen, and identified by likelyhood ratio test $(p<0.05$; decrease in objective function value of 3.84 points), pharmacokinetic parameter estimate endpoint, and goodness-of-fit plots. The interindividual variability of the blood PK model was assumed log-linear and optimized by taking possible correlation between parameters into account, and by testing the intraindividual variability through an additive error model versus a constant coefficient of variation model. The individual parameter estimates of the blood PK model allowed estimation of intercompartmental clearance and volume of distribution in the brain compartment. Population parameter estimates were assumed to be normally distributed, and 
Table I. Colouration of Several Tissues After Intranasal Administration of $30 \mu 10.5 \%$ Evan's Blue in $30 \mathrm{~s}$

\begin{tabular}{|c|c|c|c|c|c|c|c|c|c|c|c|c|}
\hline Score & Nose tip & Lungs & $\begin{array}{l}\text { Olfactory } \\
\text { bulb }\end{array}$ & $\begin{array}{l}\text { Right } \\
\text { cribriform } \\
\text { plate }\end{array}$ & $\begin{array}{l}\text { Left } \\
\text { cribriform } \\
\text { plate }\end{array}$ & $\begin{array}{l}\text { Right } \\
\text { nasal } \\
\text { cavity }\end{array}$ & $\begin{array}{l}\text { Left } \\
\text { nasal } \\
\text { cavity }\end{array}$ & Esophagus & Bowels & Stomach & Tongue & Palate \\
\hline 0 & 5 & 26 & 26 & 1 & 2 & 0 & 18 & 6 & 7 & 3 & 3 & 2 \\
\hline 1 & 22 & 1 & 1 & 26 & 25 & 0 & 4 & 21 & 20 & 23 & 24 & 25 \\
\hline 2 & 0 & 0 & 0 & 0 & 0 & 1 & 3 & 0 & 0 & 1 & 0 & 0 \\
\hline 3 & 0 & 0 & 0 & 0 & 0 & 25 & 1 & 0 & 0 & 0 & 0 & 0 \\
\hline
\end{tabular}

Tissue of 27 rats has been observed for full, medium, light, or no colouration scored by 3, 2, 1, and 0 respectively. The table shows the number of rats with accompanying scores.

considered equal when the $95 \%$ confidence intervals of the parameter estimates overlap (1.96 times the standard error).

\section{RESULTS}

\section{Evan's Blue}

Of the 27 rats that had received Evans Blue through the intranasal probe in the right nasal cavity, one had a broken septum and was excluded in the determination of the nasal coloration. One animal experienced blocking of the intranasal probe, thereby decreasing the amount of Evan's Blue reaching the right nasal cavity. Full coloration of the right nasal cavity was observed in $96 \%$ of the animals. The nose tip, tongue, palate and intestine were light colored in $81 \%, 89 \%$, $93 \%$, and $79 \%$ of the animals respectively. In the left nasal cavity $67 \%$ was not colored. In $96 \%$ of the animals the lungs as well as the olfactory bulb were not colored. Table I shows all the acquired data.

\section{Corticosterone as Biomarker for Stress}

Geometric mean ( \pm S.E.M.) of CORT concentrations in plasma at $t=0$ were $166 \pm 14 \mathrm{ng} / \mathrm{ml}(n=33)$. The groups did not

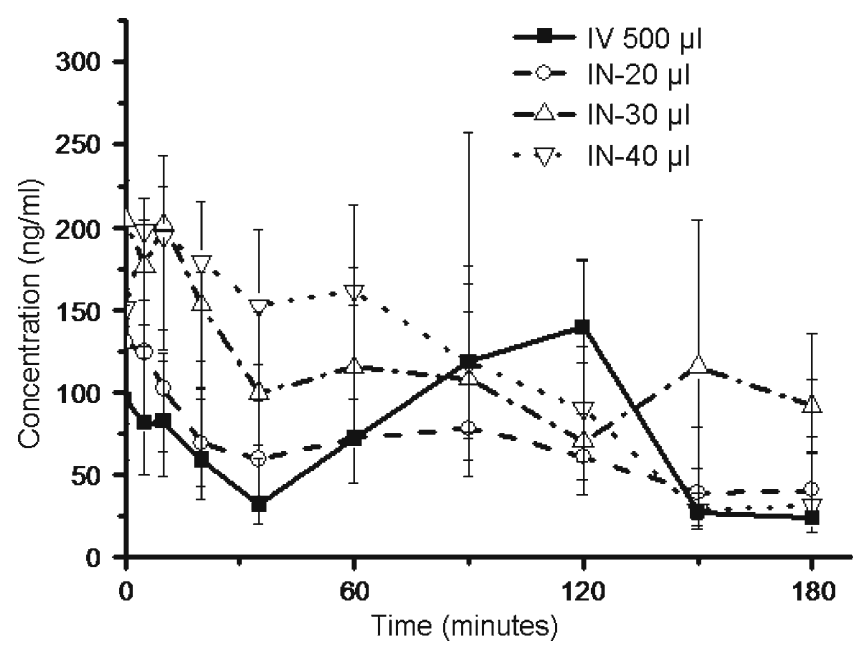

Fig. 2. Concentration-time profiles of corticosterone (geometric mean \pm S.E.M.) in plasma after intranasal administration of different volumes of saline (IN-20, -30 , and $-40 \mu \mathrm{l}$ ), compared to intravenous $(\mathrm{IV}-500 \mu \mathrm{l})$ administration. Single factor ANOVA proves no differences between the groups $(p>0.23) . n=9,9,8$, and 6 for the IV, IN$20 \mu \mathrm{l}, \mathrm{IN}-30 \mu \mathrm{l}$, and IN-40 $\mu \mathrm{l}$ groups respectively. show significant differences ( $p$-values $>0.23$ ) over the time period of $180 \mathrm{~min}$ (Fig. 2).

\section{Acetaminophen as Model Compound}

The log-normal geometric mean-time profiles of the concentrations in plasma after administration of acetaminophen (Fig. 3) showed the same profiles for all groups. At $t=$ $10 \mathrm{~min}$ there were differences between the groups when tested IV vs $30 \mu \mathrm{l}, 20 \mu \mathrm{l} v s 30 \mu \mathrm{l}$, and $20 \mu \mathrm{l} v s 40 \mu \mathrm{l}$ (P-values are $0.04,0.00$, and 0.02 respectively). At $t=180$ differences were found between IV and $20 \mu \mathrm{l}, 20 \mu \mathrm{l} v s 30 \mu \mathrm{l}$, and $20 \mu \mathrm{l} v \mathrm{~s}$ $40 \mu \mathrm{l}$ (P-values were $0.00,0.04$, and 0.02 respectively). Areas under the curve (AUC) in plasma with their standard error of the means were calculated (Fig. 4); 10.5 $\pm 0.7,11.6 \pm 0.6,8.8 \pm$ 0.9 , and $9.6 \pm 0.8\left(\mu \mathrm{g}^{*} \mathrm{~min}\right) / \mathrm{ml}$ for IV, 20, 30, and $40 \mu \mathrm{l} \mathrm{IN}$ administration respectively. No statistically significant differences between the groups were found $(P=0.07)$.

After measuring and plotting the geometric mean $( \pm$ S.E. M., Fig. 3) of acetaminophen brain microdialysate concentrations over time, single factor ANOVA revealed a differ-

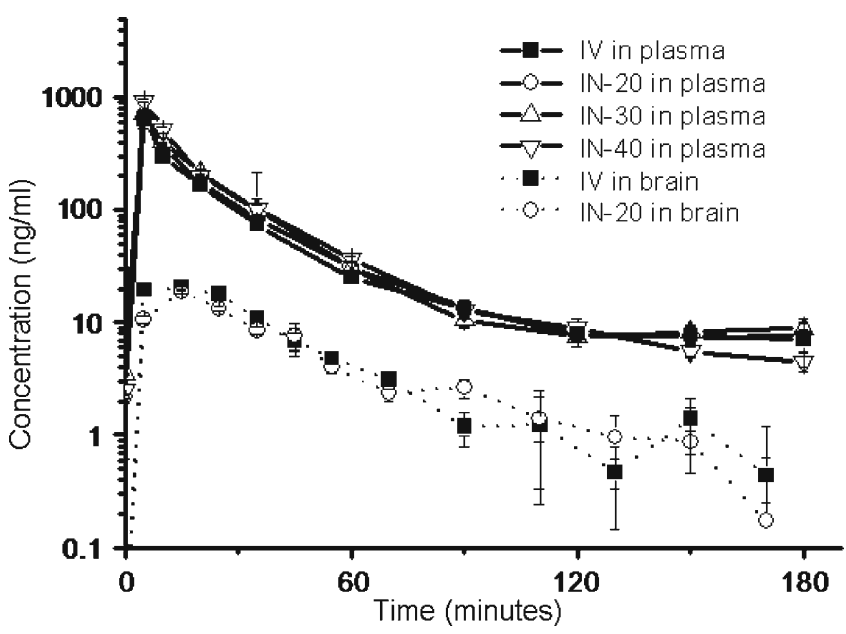

Fig. 3. Concentration-time profiles (geometric means \pm S.E.M.) of acetaminophen in plasma and brain microdialysate after intranasal (IN) administration of $200 \mu \mathrm{g}$ acetaminophen in different volumes, compared to intravenous (IV) administration. At $t=10$ min concentrations in plasma (solid line) differed when tested IV vs. IN-30 $\mu \mathrm{l}$, IN-20 $\mu \mathrm{l} v s$. IN-30 $\mu \mathrm{l}$, and IN-20 $\mu \mathrm{l} v s$. IN-40 $\mu \mathrm{l}(p=0.04,0.00$, and 0.02 respectively). At $t=180$ differences were found between IV and $20 \mu \mathrm{l}$, $20 \mu \mathrm{l} v s 30 \mu \mathrm{l}$, and $20 \mu \mathrm{l} v s 40 \mu \mathrm{l}$ ( $p=0.00,0.04$ and 0.02 respectively). In the brain microdialysates (dotted line) differences were found at $t=$ 5,35 , and $90 \min (p=0.00,0.04$, and 0.03 respectively). 


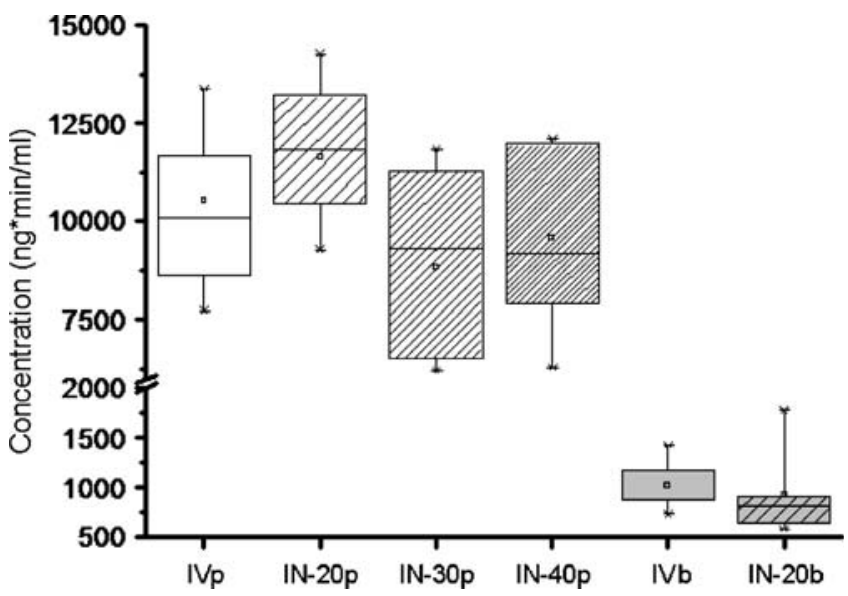

Fig. 4. Boxplots of the Area's Under the Curve (AUC) of acetaminophen concentration-time profiles in plasma (p) and brain microdialysate(b), following intranasal (IN) administration of $200 \mu \mathrm{g}$ acetaminophen in different volumes $(-20,-30$, and $-40 \mu \mathrm{l})$, compared to intravenous (IV) administration. No differences between plasma AUC's were found ( $p>0.07)$. The AUC's of the brain microdialysates also show no difference $(p=0.98)$.

ence in profiles at $t=5,35$ and $90 \mathrm{~min}$ (P-values were 0.00, 0.04 and 0.03 respectively). The maximal brain microdialysate acetaminophen concentration was reached earlier after intravenous administration. Microdialysis in vitro recovery was $40 \%$. The mean AUCs \pm S.E.M. of the brain concentrations were $2.54 \pm 0.31\left(\mu \mathrm{g}^{*} \mathrm{~min}\right) / \mathrm{ml}$ and $2.55 \pm 0.44(\mu \mathrm{g} * \mathrm{~min}) / \mathrm{ml}$ for the control group and experimental group receiving $20 \mu \mathrm{l}$ solution respectively and did not differ (Fig. 4, $p=0.98$ ). The absolute recovery of acetaminophen was $95 \%$.

After comparing several models, a 2-compartment model with the brain compartment as an effect compartment, constant coefficient of variation for intraindividual variablility and correlation between the clearance and volume of distribution of compartment 1 and 3 proved to fit the data best for both the experimental and the control study. Estimating interindividual variability on clearance and volume of distribution in effect compartment 2 did only improve the model (decrease in objective function value $>3.84$ ) of intranasal administration. Parameter estimates with their 95\% confidence interval aquired from NONMEM are listed in Table II.

\section{DISCUSSION}

The aim of this study was to develop and validate a new preclinical, refined minimal stress animal model, in which we can administer compounds intranasally and intravenously, with blood- and brain ECF samples to be taken over time. Our results indicate that IN administration in freely moving rats does not induce stress, while for the model compound acetaminophen it was observed that the pharmacokinetics following IN and IV administration were similar.

\section{Evan's Blue}

Evan's Blue is a dye with a high affinity for albumin which is present in nasal mucosa. Besides the expected full colouration of the targeted nasal cavity, $93 \%$ of the animals showed light coloration of the palate caused by leakage through the nasopalatine duct that connects the nose and mouth. This might be an indication for buccal absorption in rats. which should be considered in the PK and extrapolation of data to clinical situations, since in humans the nasopalatine duct does not extend to the mouth. However, due to its role, in cooperation with the vomeronasal organ, in food recognition, sex recognition, and courtship we found it not advisable to close the nasopalatine duct (28). Also, after the $10 \mathrm{~min}$ following Evans Blue administration a small part was swallowed, which could indicate the possibility of partial oral uptake after intranasal administration. This can be caused by passive leakage to the oesophagus and/or active sweeping by the cilia in the nose. Since rats are obligate nose breathers (29) this obviously cannot be prevented in freely moving animals. The concentration-time curves of acetaminophen however, excluded substantial uptake of compound through oral absorption. Use of other (more viscous) formulations could possibly eliminate this problem in future research.

Table II. Population Model Parameter Values

\begin{tabular}{|c|c|c|c|c|c|c|c|c|}
\hline & & \multicolumn{5}{|c|}{ Blood and peripheral pharmacokinetic mode } & \multicolumn{2}{|c|}{ Brain pharmacokinetic model } \\
\hline & & CL1 (L/h) & $\mathrm{V} 1(\mathrm{~L})$ & CL2 (L/h) & $\mathrm{V} 2(\mathrm{~L})$ & $\mathrm{KA}(\mathrm{mg} / \mathrm{h})$ & Q3 (L/h) & $\mathrm{V} 3(\mathrm{ml})$ \\
\hline \multirow[t]{2}{*}{$\theta$} & IV & $0.86 \pm 0.12$ & $0.19 \pm 0.05$ & $0.27 \pm 0.21$ & $0.07 \pm 0.02 *$ & & $8.32 \pm 5.3$ & $1050 \pm 300$ \\
\hline & IN & $0.89 \pm 0.11$ & $0.17 \pm 0.04$ & $0.40 \pm 0.06$ & $0.13 \pm 0.03$ & $86.3 \pm 19.4$ & $2.63 \pm 1.96$ & $886 \pm 286$ \\
\hline \multirow[t]{2}{*}{$\eta^{2}$} & IV & $0.03 \pm 0.03$ & $0.07 \pm 0.06$ & - & - & - & $0.62 \pm 0.53$ & $0.16 \pm 0.12$ \\
\hline & IN & $0.09 \pm 0.07$ & $0.31 \pm 0.21$ & - & $0.16 \pm 0.15$ & - & $0.88 \pm 1.20$ & $0.19 \pm 0.22$ \\
\hline \multirow[t]{2}{*}{$\varepsilon^{2}$} & IV & & & $0.01 \pm 0.005$ & & & $0.05 \pm 0.02$ & \\
\hline & IN & & & $0.02 \pm 0.01$ & & & $0.06 \pm 0.04$ & \\
\hline
\end{tabular}

Data represented are population parameter estimates $(\theta)$ with their interindividual variability $\left(\eta^{2}\right)$ and the population intraindividual variability $\left(\varepsilon^{2}\right)$ with their $95 \%$ confidence interval after intravenous (IV) or intranasal (IN) administration of $200 \mathrm{mg}$ acetaminophen. Parameters of the first central compartment are clearance (CL1) and volume of distribution (V1). For the second peripheral compartment clearance (CL2) and volume of distribution (V2) were determined, as well as the absorption rate constant (KA) after IN administration. In the brain the intercompartmental clearance $(\mathrm{Q})$ and volume of distribution (V3) were estimated. Parameter estimates that differ between the studies are denoted with * 


\section{Corticosterone}

In our study, the CORT data show no influence of administration techniques, nor of volume of administration. Cano et al. (18) performed a circadian rhythm study concerning the CORT concentrations in Wistar rats during high-fat induced stress and compared it to a normally fed control group. In that study, plasma concentrations of CORT were found to be $283 \pm 35 \mathrm{ng} / \mathrm{ml}$ (means \pm S.E.M.) in the control group, with an amplitude of $97 \pm 11 \mathrm{ng} / \mathrm{ml}$, versus $456 \pm$ $42 \mathrm{ng} / \mathrm{ml}$ in the experimental group, showing a significant difference compared to the control group $(p<0.01)$. Also, in that study, CORT concentrations were roughly $200 \mathrm{ng} / \mathrm{ml}$ straight after onset of the light phase, indicating higher basal concentrations when compared with our experiments $166 \pm$ $14 \mathrm{ng} / \mathrm{ml}$ (basal average \pm S.E.M.). Additionally, Perello et al. (30) discovered in individually housed Wistar rats, after decapitation under conditions of minimal stress after the onset of the light phase, basal concentrations of $363 \pm 35 \mathrm{ng} / \mathrm{ml}$ (means \pm S.E.M.) in animals. This was significantly higher when compared to their group-housed animals (206 \pm 32$)$ and to our individually housed freely moving animals. Perello et al. (30) stated their CORT concentrations to be low when compared to restraining studies and bacterial lipopolysaccharide injection. In our freely moving animals, we find no evidence that stress levels are increased due to our handling techniques or experiments, moreover, when compared to aforementioned studies, we have less CORT release indicating less stress.

\section{Acetaminophen}

In principle, differences in the concentration time profiles in both plasma and brain data can be explained by the absorption phase over the nasal epithelium versus IV administration, as well as by the difference in infusion time. Equal plasma AUCs indicate that the same amount of drug as IV is absorbed after IN administration. Althought differences are found when testing data per time point, the comparison of the concentration-time profiles with NONMEM show no differences in parameter estimates, except for V2. Adding interindividual variability for $\mathrm{V} 2$ in the IV model did not increase the predictability and was therefore left out of the model, but this can cause the difference in the population estimates for $\mathrm{V} 2$ since adding interindividual variability did improve the IN model. The individual- and population estimates described the data well. We can consider the free drug concentrations in the ECF in terms of intercompartmental clearance (Q3) and V3, which gives us information on the blood-brain-barrier transport and whether direct transport from the nasal epithelium into the brain could be an issue. Since the plasma pharmacokinetics after IV and IN administration are similar, increased CNS target site bioavailability after IN administration should result in increased brain concentrations after IN administration compared to IV administration, which is not the case.

Acetaminophen is subject to metabolization by $\mathrm{P} 450$, that is highly present in the nasal epithelium (31), but this did not influence the PK of acetaminophen following intranasal administration relative to that following intravenous dosing. Furthermore, we found no evidence of substantial buccal or oral absorption in the concentration-time profiles of acetaminophen. The population estimates of the brain showed no differences in intercompartmental clearance, volume of distribution, interindividual- or intraindividual variability.

\section{CONCLUSIONS}

The animals showed clear coloration in the right nasal cavity, so after intranasal administration, the major part of the administered $30 \mu \mathrm{l}$ Evan's Blue remained in the nasal cavity and the cannula can be used to administer compounds in the right nasal cavity in freely moving animals, with little or no drainage to other absorption sites.

When compared to other studies reported in literature, our experimental and handling techniques resulted in lower CORT concentrations, which indicates less stress during the experiments in freely moving animals. The intranasal administration did not increase CORT concentrations, and there were no differences in CORT concentrations when volumes up to $40 \mu \mathrm{l}$ are administered, compared to IV administration.

With respect to the plasma and brain pharmacokinetics of acetaminophen we conclude that following IN administration no evidence was found for selective distribution enhancement to the brain. The administration of acetaminophen is site specific, as also concluded from the Evan's Blue study. We do emphasize however that the administration of acetaminophen by the intranasal route shows a very rapid absorption indicated by identical PK when compared to IV administration.

In summary, the new intranasal administration method in freely moving animals allows the local, stress free administration of acetaminophen, while blood and brain pharmacokinetics can be observed over time.

\section{ACKNOWLEDGMENTS}

This work was supported by the Leiden/Amsterdam Center for Drug Research (Leiden, The Netherlands) and Pfizer Global Research and Development (Sandwich, England).

Open Access This article is distributed under the terms of the Creative Commons Attribution Noncommercial License which permits any noncommercial use, distribution, and reproduction in any medium, provided the original author(s) and source are credited.

\section{REFERENCES}

1. American Academy of Pediatrics. Comittee on drugs. Alternative routes of drug administration-advantages and disadvantages (subject review). Pediatrics 1997;100:143-52. doi:10.1542/ peds. 100.1.143.

2. Graff CL, Pollack GM. Nasal drug administration: potential for targeted central nervous system delivery. J Pharm Sci. 2005;94:1187-95. doi:10.1002/jps.20318.

3. Jansson B, Bjork E. Visualization of in vivo olfactory uptake and transfer using fluorescein dextran. J Drug Target. 2002;10:379-86. doi:10.1080/1061186021000001823.

4. Veronesi MC, Kubek DJ, Kubek MJ. Intranasal delivery of a thyrotropin-releasing hormone analog attenuates seizures in the amygdala-kindled rat. Epilepsia 2007;48:2280-6. 
5. Dahlin M, Jansson B, Bjork E. Levels of dopamine in blood and brain following nasal administration to rats. Eur $\mathrm{J}$ Pharm Sci. 2001;14:75-80. doi:10.1016/S0928-0987(01)001518.

6. Dufes C, Olivier JC, Gaillard F, Gaillard A, Couet W, Muller JM. Brain delivery of vasoactive intestinal peptide (VIP) following nasal administration to rats. Int $\mathrm{J}$ Pharm. 2003;255:87-97. doi:10.1016/S0378-5173(03)00039-5.

7. van den Berg M, Merkus P, Romeijn S, Verhoef JC, Merkus F. Uptake of melatonin into the cerebrospinal fluid after nasal and intravenous delivery: studies in rats and comparison with a human study. Pharm Res. 2004;21:799-802. doi:10.1023/B: PHAM.0000026431.55383.69.

8. Shi Z, Zhang Q, Jiang X. Pharmacokinetic behavior in plasma, cerebrospinal fluid and cerebral cortex after intranasal administration of hydrochloride meptazinol. Life Sci. 2005;77:257483. doi:10.1016/j.lfs.2005.02.025.

9. Raphael JH, Strupish J, Selwyn DA, Hann HCL, Langton JA. Recovery of respiratory ciliary function after depression by inhalation anaesthetic agents: an in vitro study using nasal turbinate explants. Br J Anaesth. 1996;76:854-9.

10. Schipper NGM, Verhoef JC, Merkus FWHM. The nasal mucociliary clearance: relevance to nasal drug delivery. Pharm Res. 1991;8:807-14. doi:10.1023/A:1015830907632.

11. Selwyn DA, Raphael JH, Lambert DG, Langton JA. Effects of morphine on human nasal cilia beat frequency in vitro. $\mathrm{Br} \mathrm{J}$ Anaesth. 1996;76:274-7.

12. Raphael JH, Selwyn DA, Mottram SD, Langton JA, O'Callaghan C. Effects of $3 \mathrm{MAC}$ of halothane, enflurane and isoflurane on cilia beat frequency of human nasal epithelium in vitro. $\mathrm{Br} \mathrm{J}$ Anaesth. 1996;76:116-21.

13. Raphael JH, Butt MW. Comparison of isoflurane with propofol on respiratory cilia. Br J Anaesth. 1997;79:473-5.

14. Schindler E, Müller M, Zickmann B, Kraus H, Reuner KH, Hempelmann G. Blood supply to the liver in the human after 1 MAC desflurane in comparison with isoflurane and halothane. Anasthesiol Intensivmed Notfallmed Schmerzther. 1996;31:3448. doi:10.1055/s-2007-995933.

15. Lennox P, Hern J, Birchall M, Lund V. Local anaesthesia in flexible nasendoscopy. A comparison between cocaine and cophenylcaine. J Laryngol Otol. 1996;110:540-2. doi:10.1017/ S0022215100134206.

16. Sapolsky RM, Romero LM, Munck AU. How do glucocorticoids influence stress responses? Integrating permissive, suppressive, stimulatory, and preparative actions. Endocr Rev. 2000;21:55-89. doi:10.1210/er.21.1.55.

17. Ugwoke MI, Verbeke N, Kinget R. The biopharmaceutical aspects of nasal mucoadhesive drug delivery. J Pharm Pharmacol. 2001;53:3-21. doi:10.1211/0022357011775145.
18. Cano P, Jimenez-Ortega V, Larrad A, Reyes Toso CF, Cardinali DP, Esquifino AI. Effect of a high-fat diet on 24-h pattern of circulating levels of prolactin, luteinizing hormone, testosterone, corticosterone, thyroid-stimulating hormone and glucose, and pineal melatonin content, in rats. Endocr 2008;33:118-25. doi:10.1007/s12020-008-9066-x.

19. de Lange EC, Danhof M, de Boer AG, Breimer DD. Critical factors of intracerebral microdialysis as a technique to determine the pharmacokinetics of drugs in rat brain. Brain Res. 1994;666:1-8. doi:10.1016/0006-8993(94)90276-3.

20. Schaiquevich P, Niselman V, Tumilasci O, Modesto R. Evaluation of acetaminophen P-glycoprotein-mediated salivary secretion by rat submandibular glands. Arch Oral Biol. 2004;49:895-901.

21. Kandimalla KK, Donovan MD. Localization and differential activity of p-glycoprotein in the bovine olfactory and nasal respiratory mucosae. Pharm Res. 2005;22:1121-8. doi:10.1007/ s11095-005-5420-3.

22. Graff CL, Pollack GM. Functional evidence for p-glycoprotein at the nose-brain barrier. Pharm Res. 2005;22:86-93. doi:10.1007/ s11095-004-9013-3.

23. van Bree JB, Baljet AV, van Geyt A, de Boer AG, Danhof M, Breimer DD. The unit impulse response procedure for the pharmacokinetic evaluation of drug entry into the central nervous system. J Pharmacokinet Biopharm. 1989;17:441-62. doi:10.1007/BF01061457.

24. Moghaddam B, Bunney BS. Ionic composition of microdialysis perfusing solution alters the pharmacological responsiveness and basal outflow of striatal dopamine. J Neurochem. 1989;53:652-4. doi:10.1111/j.1471-4159.1989.tb07383.x.

25. Lew M. Good statistical practice in pharmacology Problem 1. Br J Pharmacol. 2007;152:295-8. doi:10.1038/sj.bjp. 0707370.

26. Flynn FV, Piper KA, Garcia-Webb P, McPherson K, Healy MJ The frequency distributions of commonly determined blood constituents in healthy blood donors. Clin Chim Acta. 1974;52:163-71. doi:10.1016/0009-8981(74)90206-X.

27. Lars L, Jakob R, Niclas J. Perl-speaks-NONMEM (PsN)-a Perl module for NONMEM related programming. Comput Methods Programs Biomed. 2004;75:85-94. doi:10.1016/j.cmpb.2003.11.003.

28. Jacob S, Zelano B, Gungor A, Abbott D, Naclerio R, McClintock MK. Location and gross morphology of the nasopalatine duct in human adults. Arch Otolaryngol Head Neck Surg. 2000;126:741-8.

29. Krinke GJ (2000) The laboratory rat. Academic Press, London, United Kingdom.

30. Perello M, Chacon F, Cardinali DP, Esquifino AI, Spinedi E. Effect of social isolation on 24-h pattern of stress hormones and leptin in rats. Life Sci. 2006;78:1857-62. doi:10.1016/j.lfs.2005.08.029.

31. Sarkar MA. Drug metabolism in the nasal mucosa. Pharm Res. 1992;9:1-9. doi:10.1023/A:1018911206646. 